\title{
MAPK and SHH pathways modulate type 3 deiodinase expression in papillary thyroid carcinoma
}

\author{
Mírian Romitti', Simone Magagnin Wajner', Lucieli Ceolin', Carla Vaz Ferreira', \\ Rafaela Vanin Pinto Ribeiro', Helena Cecin Rohenkohl', Shana de Souto Weber', \\ Patrícia Luciana da Costa Lopez ${ }^{2}$, Cesar Seigi Fuziwara ${ }^{3}$, Edna Teruko Kimura ${ }^{3}$ \\ and Ana Luiza Maia'
}

${ }^{1}$ Thyroid Section, Endocrine Division, Serviço de Endocrinologia, Hospital de Clínicas de Porto Alegre, Universidade Federal do Rio Grande do Sul, Rua Ramiro Barcelos, 2350, CEP 90035-003 Porto Alegre, RS, Brazil

${ }^{2}$ Experimental Research Center, Hospital de Clínicas de Porto Alegre, Universidade Federal do Rio Grande do Sul, Porto Alegre, RS, Brazil

${ }^{3}$ Department of Cell and Developmental Biology, Institute of Biomedical Sciences, Universidade de São Paulo, São Paulo, SP, Brazil
Correspondence should be addressed to A L Maia Email almaia@ufrgs.br

\begin{abstract}
Type 3 deiodinase (DIO3, D3) is reactivated in human neoplasias. Increased D3 levels in papillary thyroid carcinoma (PTC) have been associated with tumor size and metast atic disease. The objective of this study is to investigate the signaling pathways involved in $\mathrm{DIO} 3$ upregulation in PTC. Experiments were performed in human PTC cell lines (K1 and TPC-1 cells) or tumor samples. DIO3 mRNA and activity were evaluated by real-time PCR and ion-exchange column chromatography respectively. Western blot analysis was used to determine the levels of D3 protein. DIO3 gene silencing was performed via siRNA transfection. DIO3 mRNA levels and activity were readily detected in $\mathrm{K} 1$ (BRAF $^{\mathrm{V} 600 \mathrm{E}}$ ) and, at lower levels, in TPC-1 (RET/PTC1) cells ( $P<0.007$ and $P=0.02$ respectively). Similarly, DIO3 mRNA levels were higher in PTC samples harboring the $B R A F^{V 600 E}$ mutation as compared with those with RET/PTC1 rearrangement or negative for these mutations $(P<0.001)$. Specific inhibition of $B R A F$ oncogene (PLX4032, $3 \mu \mathrm{M})$, MEK (U0126, 10-20 $\mu \mathrm{M}$ ) or p38 (SB203580, 10-20 $\mu \mathrm{M})$ signaling was associated with decreases in DIO3 expression in $\mathrm{K} 1$ and TPC-1 cells. Additionally, the blockage of the sonic hedgehog (SHH) pathway by cyclopamine $(10 \mu \mathrm{M})$ resulted in markedly decreases in DIO3 mRNA levels. Interestingly, siRNA-mediated DIO3 silencing induced decreases on cyclin D1 expression and partial G1 phase cell cycle arrest, thereby downregulating cell proliferation. In conclusion, sustained activation of the MAPK and SHH pathways modulate the levels of DIO3 expression in PTC. Importantly, DIO3 silencing was associated with decreases in cell proliferation, thus suggesting a D3 role in tumor growth and aggressiveness.
\end{abstract}
Key Words
- type 3 deiodinase, papillary thyroid carcinoma
- MAPK genetic alterations
- Sonic Hedgehog pathway

Endocrine-Related Cancer (2016) 23, 135-146

\section{Introduction}

Thyroid hormone (TH) influences a wide variety of biological processes including the balance between cell proliferation and differentiation. $\mathrm{TH}$ homeostasis is critically regulated by the synchronized activity of the iodothyronine deiodinases. Type 1 (DIO1, D1) and type 2 deiodinases (DIO2, D2) catalyze the conversion of the 
pro132-hormone thyroxine $\left(\mathrm{T}_{4}\right)$ into the biologically active form triiodothyronine $\left(\mathrm{T}_{3}\right)$ via outer ring deiodination. In contrast, type 3 iodothyronine deiodinase (DIO3, D3) catalyzes the inactivation of $\mathrm{T}_{4}$ and $\mathrm{T}_{3}$ via inner ring deiodination (Maia et al. 2011). Several studies have shown an association between thyroidal status and tumor pathogenesis (Pinto et al. 2011, Kim \& Cheng 2013) while several reports have documented changes in the expression of deiodinases in benign and malignant tumors (Huang et al. 2001, Murakami et al. 2001, de Souza Meyer et al. 2005, Dentice et al. 2007, 2012, Meyer et al. 2007).

D3, a known fetal protein, is reactivated in human neoplasias and has been associated with tumor behavior. The upregulation of DIO3 gene occurs at the transcriptional level, and it might be driven by disruption of several signaling pathways such as MAPK, transforming growth factor beta (TGFB), sonic hedgehog (SHH) and B-catenin (Dentice \& Salvatore 2011). Increased levels of D3 were demonstrated in mouse and human malignant basal cell carcinoma (BCC). In BCC, the DIO3 induction occurs via activation of the SHH/GLI pathway and is associated with increased levels of cyclin D1 and keratinocyte proliferation (Dentice et al. 2007). High levels of DIO3 mRNA also occur in human intestinal adenomas and carcinomas (Dentice et al. 2012). Interestingly, the activating TH enzyme, D2, was downregulated by SHH and B-catenin activation. Thus, this opposite but convergent action of D2 and D3 enzymes seems to contribute to the local $\mathrm{TH}$ attenuation, leading to proliferative effects.

Papillary thyroid carcinoma (PTC) is the most common malignant thyroid tumor, occurring in $85-90 \%$ of cases (Pellegriti et al. 2013). Aberrant activation of MAPK pathway is a hallmark in PTC. The $B R A F^{V 600 E}$ mutation is the most common genetic event, observed in $\sim 50 \%$ of PTC, while RET/PTC rearrangement occurs in $\sim 20 \%$ and RAS mutations in $10-15 \%$ of cases (Kimura et al. 2003, Fagin \& Mitsiades 2008). Increased levels of D3 were shown in PTC and associated with advanced disease (Romitti et al. 2012). Augmented D3 levels were also observed in follicular thyroid carcinoma but not in medullary or anaplastic thyroid carcinoma samples. The reasons for these distinct patterns of D3 expression is still lacking.

In the present study, we sought to determine the signaling pathways involved in DIO3 upregulation in PTC as well as to investigate whether DIO3 induction is associated with neoplastic thyroid cell proliferation.

\section{Material and methods}

\section{Cell culture}

Studies evaluating DIO3 gene regulation were performed in two human PTC-derived cell lines, which endogenously express the DIO3 gene: K1 cell line (European Collection of Cell Cultures; ECACC, Porton Down, Salisbury, UK), which carries the $B R A F^{V 600 E}$ mutation, and TPC-1 cells (kindly provided by Dr J A Fagin to Dr E T Kimura, Memorial Sloan Kettering Cancer Center, New York, NY; Human Oncology and Pathogenesis Program, Memorial Sloan-Kettering Cancer Center, New York, NY, USA) harboring the RET/PTC1 rearrangement (Geraldo et al. 2012). The origin in human PTC and gene expression profile have already been demonstrated for both cell lines (Schweppe et al. 2008, Saiselet et al. 2012). K1 cells were grown in DMEM: Ham's F12:MCDB 105 (2:1:1 (Life Technologies, Invitrogen)) plus $2 \mathrm{mM}$ glutamine and 10\% fetal bovine serum (FBS) (Life Technologies, Invitrogen). TPC-1 cells were grown in DMEM containing 10\% FBS. Additionally, we used a human medullary thyroid carcinoma (MTC) cell line carrying the RET C634Y mutation - TT cells (Carlomagno et al. 1995; American Type Culture Collection, ATCC, Manassas, VA, USA) - to determine the effect of SHH on DIO3 reactivation. TT cells were grown in RPMI (Life Technologies, Invitrogen) medium supplemented with $10 \%$ FBS. All experiments were performed between passages $15-25$ for K1 cells, 20-25 for TPC- 1 cells and 10-15 for TT cells. All cells were maintained at $37^{\circ} \mathrm{C}$ in a humidified atmosphere of $5 \% \mathrm{CO}_{2}$ and $95 \%$ air, and the culture medium was changed three times a week. Experiments were performed in cell cultures at $60-80 \%$ confluence. All analyses were performed in triplicate in at least three independent experiments.

\section{Human PTC samples}

Neoplastic tissues were collected from 25 unselected PTC patients who underwent thyroidectomy at our institution. Non-tumor thyroid tissues adjacent to tumor were also collected. All PTC and normal tissue samples $(n=9)$ were examined by a pathologist to exclude the presence of necrosis and/or inflammation. Tumors were histologically classified according to WHO recommendations (Hedinger et al. 1989). The Ethical Committee of the Hospital de Clínicas de Porto Alegre, Porto Alegre, Brazil, approved the study.

\section{BRAF $^{\mathrm{V} 600 \mathrm{E}}$ mutation and RET/PTC rearrangement analysis}

DNA was extracted from $10-\mu \mathrm{m}$ slides of paraffinembedded tissue blocks, using the Magnesil Genomic

Published by Bioscientifica Ltd 
Fixed Tissue System (Promega Corporation), according to the manufacturer's instructions. The BRAF exon 15 was amplified by PCR using specific oligonucleotides (Supplementary Table S1, see section on supplementary data given at the end of this article). For PCR amplification, we used $50-100 \mathrm{ng} / \mu \mathrm{l}$ of DNA in a reaction mix $(25 \mu \mathrm{l})$ containing $20 \mathrm{mM}$ Tris- $\mathrm{HCl}$ (pH 8.0), $50 \mathrm{mM} \mathrm{KCl}, 2 \mathrm{mM}$ $\mathrm{MgCl}_{2}, 0.2 \mathrm{mM}$ dNTPs, $0.2 \mathrm{mM}$ of each primer and $1.25 \mathrm{U}$ Platinum Taq DNA polymerase (Invitrogen). BRAF V600E mutation genotyping was performed by direct sequencing (Life Technologies, Applied Biosystems).

For RET/PTC1 detection, total RNA was extracted from PTC samples using the Trizol Reagent, and cDNA was generated using the Super Script III First-Strand Synthesis System (Life Technologies, Invitrogen, Carlsbad, CA, USA). Detection of RET/PTC1 rearrangement was performed by RT-PCR. We used the forward primer for $\mathrm{H} 4$ gene and the reverse primer for the tyrosine kinase domain of RET (Supplementary Table S1). PCR conditions were performed according to a previously described protocol (Sapio et al. 2007). Afterwards, $10 \mu \mathrm{l}$ of the PCR product were analyzed by electrophoresis in a $1.5 \%$ agarose gel. TPC-1 cells were used as a positive control. Positive samples were subjected to direct sequencing to confirm the presence of RET/PTC rearrangement.

\section{Immunohistochemistry studies}

D3 expression was evaluated by immunohistochemistry studies in matched normal thyroid tissue, primary PTC tumor and lymph node metastases from two PTC patients ( $n=18$ and $n=19 ;$ Table 1). Immunohistochemistry analysis of D3 was performed on $6-\mu \mathrm{m}$ sections of formalin-fixed and paraffin-embedded tissues. The immunohistochemical technique comprised tissue deparaffinization and rehydration, antigenic recovery, inactivation

Table 1 Clinical and oncological features of the patients with PTC

\begin{tabular}{c}
$\begin{array}{c}\text { Tumor } \\
\text { size }(\mathrm{cm})\end{array}$ \\
\hline 1.5 \\
1.3 \\
2.3 \\
\\
1.0 \\
6.4 \\
2.5 \\
\\
0.8 \\
2.7 \\
2.5 \\
2.3 \\
3.8 \\
8 \\
8
\end{tabular}

0.9

2.9

7

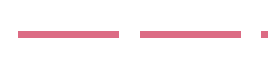$$
\begin{aligned}
& 6 \\
& 7 \\
& 8 \\
& 9 \\
& 10 \\
& 11 \\
& 12 \\
& 13
\end{aligned}
$$$$
\begin{aligned}
& 6 \\
& 7 \\
& 8 \\
& 9 \\
& 10 \\
& 11 \\
& 12 \\
& 13
\end{aligned}
$$$$
\begin{aligned}
& 6 \\
& 7 \\
& 8 \\
& 9 \\
& 10 \\
& 11 \\
& 12 \\
& 13
\end{aligned}
$$$$
\begin{aligned}
& 6 \\
& 7 \\
& 8 \\
& 9 \\
& 10 \\
& 11 \\
& 12 \\
& 13
\end{aligned}
$$$$
\begin{aligned}
& 6 \\
& 7 \\
& 8 \\
& 9 \\
& 10 \\
& 11 \\
& 12 \\
& 13
\end{aligned}
$$

\begin{tabular}{|c|c|c|}
\hline $\begin{array}{l}\text { Patient } \\
\text { number }\end{array}$ & Sex & $\begin{array}{c}\text { Age at } \\
\text { diagnosis } \\
\text { (years) }\end{array}$ \\
\hline 1 & $M$ & 50 \\
\hline 2 & $M$ & 22 \\
\hline 3 & $M$ & 22 \\
\hline 4 & $\mathrm{~F}$ & 33 \\
\hline 5 & $\mathrm{~F}$ & 27 \\
\hline 6 & $\mathrm{~F}$ & 36 \\
\hline 7 & $\mathrm{~F}$ & 53 \\
\hline 8 & $\mathrm{~F}$ & 42 \\
\hline 9 & $\mathrm{~F}$ & 50 \\
\hline 10 & $\mathrm{~F}$ & 47 \\
\hline 11 & $\mathrm{M}$ & 50 \\
\hline 12 & $\mathrm{~F}$ & 61 \\
\hline 13 & $\mathrm{~F}$ & 42 \\
\hline 14 & $\mathrm{~F}$ & 10 \\
\hline 15 & $\mathrm{~F}$ & 18 \\
\hline 16 & $\mathrm{~F}$ & 55 \\
\hline 17 & $\mathrm{~F}$ & 11 \\
\hline 18 & $M$ & 27 \\
\hline 19 & $\mathrm{~F}$ & 53 \\
\hline 20 & $\mathrm{~F}$ & 51 \\
\hline 21 & $M$ & 35 \\
\hline 22 & $\mathrm{~F}$ & 49 \\
\hline 23 & $\mathrm{~F}$ & 30 \\
\hline 24 & $\mathrm{~F}$ & 21 \\
\hline 25 & $\mathrm{~F}$ & 31 \\
\hline
\end{tabular}

\begin{tabular}{|c|c|c|}
\hline $\begin{array}{l}\text { Patient } \\
\text { number }\end{array}$ & Sex & $\begin{array}{c}\text { Age at } \\
\text { diagnosis } \\
\text { (years) }\end{array}$ \\
\hline 1 & $M$ & 50 \\
\hline 2 & $M$ & 22 \\
\hline 3 & $M$ & 22 \\
\hline 4 & $\mathrm{~F}$ & 33 \\
\hline 5 & $\mathrm{~F}$ & 27 \\
\hline 6 & $\mathrm{~F}$ & 36 \\
\hline 7 & $\mathrm{~F}$ & 53 \\
\hline 8 & $\mathrm{~F}$ & 42 \\
\hline 9 & $\mathrm{~F}$ & 50 \\
\hline 10 & $\mathrm{~F}$ & 47 \\
\hline 11 & $\mathrm{M}$ & 50 \\
\hline 12 & $\mathrm{~F}$ & 61 \\
\hline 13 & $F$ & 42 \\
\hline 14 & $\mathrm{~F}$ & 10 \\
\hline 15 & $\mathrm{~F}$ & 18 \\
\hline 16 & $F$ & 55 \\
\hline 17 & $\mathrm{~F}$ & 11 \\
\hline 18 & $M$ & 27 \\
\hline 19 & $\mathrm{~F}$ & 53 \\
\hline 20 & $\mathrm{~F}$ & 51 \\
\hline 21 & $M$ & 35 \\
\hline 22 & $F$ & 49 \\
\hline 23 & $F$ & 30 \\
\hline 24 & $\mathrm{~F}$ & 21 \\
\hline 25 & $\mathrm{~F}$ & 31 \\
\hline
\end{tabular}

(n)

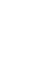$$
\text { DO: }
$$

1

\begin{tabular}{l} 
Histology \\
\hline Classic type \\
Classic type \\
Follicular \\
variant \\
Classic type \\
Classic type \\
Follicular \\
variant \\
Classic type \\
Classic type \\
Classic type \\
Classic type \\
Classic type \\
Classic type \\
Classic type
\end{tabular}

$\begin{array}{lc}\text { Classic type } & \text { I } \\ \text { Classic type } & \text { I } \\ \text { Follicular } & \text { IV } \\ \text { variant } & \\ \text { Classic type } & \text { II } \\ \text { Follicular } & \text { I } \\ \quad \text { variant } & \\ \text { Classic type } & \text { III } \\ \text { Follicular } & \text { II } \\ \quad \text { variant } & \\ \text { Classic type } & \text { I } \\ \text { Follicular } & \text { I } \\ \text { variant } & \\ \text { Classic type } & \text { I } \\ \text { Classic type } & \text { I } \\ \text { Follicular } & \text { I } \\ \text { variant } & \end{array}$

\begin{tabular}{c} 
Stage (TNM) \\
\hline III \\
II \\
I \\
II \\
I \\
I \\
I \\
II \\
II \\
III \\
IV \\
I \\
III \\
II \\
I \\
I \\
IV \\
II \\
I
\end{tabular}


of endogenous peroxidase and blockage of unspecific reactions. D3 anti-rabbit polyclonal antibody (Novus Biologicals, Littleton, CO, USA) was incubated overnight at a temperature of $4{ }^{\circ} \mathrm{C}$, at dilution of $1: 50$ (the same antibody concentration was also used for positive control), followed by subsequent incubation with biotinylated secondary antibody, streptavidin-HRP conjugate (LSAB; Dako, Carpinteria, CA, USA) and diaminobenzidine tetrahydrochloride (Kit DAB; Dako). Placenta tissue was used as a positive control. The negative control was obtained by omission of the primary antibody. The slides were examined using an Olympus BX51 microscope with an Olympus QColor 5 camera. The QCapturePro software was used to capture the images.

\section{Real-time PCR}

Total RNA was extracted from K1 and TPC-1 cells using the RNeasy minikit (Qiagen). Trizol Reagent was used for total RNA extraction from PTC samples and surrounding thyroid tissues. One microgram of RNA was reverse transcribed into cDNA using the SuperScript III FirstStrand Synthesis System for RT-PCR (Life Technologies, Invitrogen), following the manufacturer's protocol for the oligo (dT) method. RT-qPCR experiments were performed in a 7500 Fast Real-Time PCR System Thermal Cycler with 7500 FAST System Sequence Detection 1.4 Software (Life Technologies, Applied Biosystems). Experiments were performed by real-time monitoring of the increase in fluorescence of SYBR Green dye. The oligonucleotides used are described in Supplementary Table S1, see section on supplementary data given at the end of this article. Each sample was assayed in triplicate, and a negative control was included in each experiment. Standard curves representing five-point serial dilution of cDNA were analyzed and used as calibrators of the relative quantification of product generated in the exponential phase of the amplification curve. The $R^{2}$ was greater than 0.99 , while the amplification efficiency was higher than $98 \%$. Quantification of DIO3, DIO2 and GAPDH cDNA were performed by relative quantification using the comparative $\Delta \Delta C T$ method and expressed relative to the reference gene (cyclophilin A). Changes in gene expression were expressed as relative fold difference ( $n$-fold change) or as arbitrary units (AUs).

\section{Inhibition of MAPK and SHH signaling}

To evaluate the effect of MAPK signaling activation on DIO3 induction in K1 and TPC-1 cell lines, we performed studies using specific inhibitors to the signaling effectors
MEK (U0126: 10-20 $\mu$ M; Sigma-Aldrich), p38 (SB203580: 10-20 $\mu \mathrm{M}$; Sigma-Aldrich) and BRAF mutated (PLX4032: $3 \mu \mathrm{M}$; Selleck Chemicals, Houston, TX, USA). Additionally, to assess the role of the SHH pathway on DIO3 regulation, we used the specific inhibitor of the smoothened (a SHH signaling effector), cyclopamine $(10 \mu \mathrm{M}$, Sigma-Aldrich). The recombinant human SHH $(1 \mu \mathrm{g} / \mathrm{ml}$, R\&D Systems, Minneapolis, MN, USA) was used to induce SHH activation in TT cells. Controls were incubated with medium + vehicle (1\% DMSO, Sigma-Aldrich). Cells were incubated during $24 \mathrm{~h}$ and then were harvested and processed for total RNA or total protein extraction.

\section{D3 activity assay}

D3 activity was determined in PTC cells by ion-exchange column chromatography (Wajner et al. 2011). After concluding the experiments, $300 \mu \mathrm{l}$ of medium was collected, and the reaction was stopped with $200 \mu \mathrm{l}$ horse serum and $100 \mu \mathrm{l} 50 \%$ TCA, which was followed by centrifugation at $12000 \boldsymbol{g}$ for $2 \mathrm{~min}$ to precipitate the non-metabolized (125I) $\mathrm{T}_{3}$. The supernatant was used to determine (125I)T2 and (125I)T1 levels. The Sephadex LH-20 column was equilibrated with $0.1 \mathrm{M} \mathrm{HCl}$, and an equal volume of $0.1 \mathrm{M} \mathrm{HCl}$ was added to $500 \mu \mathrm{l}$ samples and then mixed. Stepwise elution was performed by successive application of $2 \times 1 \mathrm{ml}$ of $0.1 \mathrm{M} \mathrm{HCl}$ (for 125I release), $6 \times 1 \mathrm{ml}$ of $0.1 \mathrm{M} \mathrm{NaOH}-$ ethanol $(8: 1 \mathrm{v} / \mathrm{v}(125 \mathrm{I})$ for T1 release) and $4 \times 1 \mathrm{ml}$ of $50 \%$ ethanol in $0.1 \mathrm{M} \mathrm{NaOH}$ (1:1 $\mathrm{v} / \mathrm{v}$ (125I) for $\mathrm{T} 2$ release). The $1-\mathrm{ml}$ fractions were collected and counted for radioactivity. The D3 activity was calculated by multiplying the fractional conversion by the $T_{3}$ concentration in the media and expressed as $T_{3}$ inactivation ( $\mathrm{fmol} / \mathrm{mg}$ protein per $24 \mathrm{~h}$ ).

\section{Western blot analysis}

Cultured cells were lysed and prepared for western blot analysis, as previously described (Fuziwara \& Kimura 2014). Briefly, 30-50 $\mu \mathrm{g}$ protein of each sample was fractionated by $8-12 \%$ SDS-PAGE and blotted onto an Immobilon PVDF membrane (Millipore, Billerica, MA, USA). Non-specific binding sites were blocked by incubation with $5 \%$ nonfat dry milk in Tris-buffered saline $0.1 \%$ Tween-20. The following primary antibodies were used: anti-D3 (1:400; Novus Biologicals), anti-ERK1/2 (1:400; Santa Cruz Biotechnology), anti-phospho-ERK1/2 (1:400; Santa Cruz Biotechnology), anti-p38 (1:500; Cell Signaling), anti-phospho-p38 (1:200; Santa Cruz Biotechnology), anti-cyclin D1 (1:400; Santa Cruz

Published by Bioscientifica Ltd 
Biotechnology), anti-Gli1 (1:400; Cell Signaling Technology), anti- $\alpha$-tubulin B7 (1:500; Santa Cruz Biotechnology) and anti- $\beta$-actin (1:10 000; Sigma-Aldrich). The antigen-antibody complexes were visualized using HRP-conjugated secondary antibody and an enhanced chemiluminescence system (GE Healthcare, Pittsburgh, PA, USA). Expression was quantified using image densitometry with ImageJ analysis software.

\section{siRNA transfection}

siRNA studies were performed to evaluate the specific effects of DIO3 inhibition on cell proliferation. The siRNAs were as follows: Silencer Select GAPDH siRNA (\#4390849, Life Technologies, Ambion Inc., Austin, TX, USA) was used as positive control; Silencer Select Negative Control (\#4390843, Life Technologies, Ambion Inc.) and Silencer Pre-designed DIO3 siRNA (\#AM16708, Life Technologies, Ambion Inc.) were used in the experiments. Transfection studies were performed using Lipofectamine RNAiMAX reagent, according to the manufacturers' instructions (Life Technologies, Invitrogen). A total of $15 \times 10^{4}$ cells/well (K1 and TPC-1) were plated in six-well plates and transfected with 40 pmol of GAPDH siRNA, $100 \mathrm{pmol}$ of silencer negative and $100 \mathrm{pmol}$ of DIO3 siRNA. All analyses were performed in triplicate and in at least three independent experiments.

\section{Cell proliferation assays}

Absolute cell number count and flow cytometry were performed to evaluate cell proliferation. Initially, $15 \times 10^{4}$ cells/well (K1 and TPC-1) were plated in six-well plates, transfected with 100 pmol of DIO3 siRNA and incubated for $48 \mathrm{~h}$. The cells were trypsinized, and the absolute number was counted using the Neubauer chamber. To evaluate the effect of DIO3 expression on the cell cycle status, K1 cells were incubated with DIO3 siRNA. After $48 \mathrm{~h}$, cells were washed with PBS and then resuspended in $50 \mu \mathrm{g} / \mathrm{ml}$ propidium iodide and $0.1 \%$ Triton X-100 in sodium citrate solution. Cells were incubated on ice for at least $15 \mathrm{~min}$. Marked cells were analyzed using Attune NxT Acoustic Focusing Cytometer (Life Technologies, Applied Biosystems). The data generated were analyzed using the FlowJo software. All experiments were performed in triplicate.

\section{Statistical analysis}

DIO3 mRNA was expressed as AUs or fold, while D3 activity as mean \pm s.D. The number of cells in each cell cycle stage is shown as frequency. To compare D3 levels among the groups, we used $t$-test or one-way ANOVA. $\chi^{2}$ test was used to compare the differences in the proportion of cells in different stages of cell cycle. The SPSS 18.0 and Prism 5.0 software were used for all analyses, and $P<0.05$ was considered statistically significant.

\section{Results}

\section{MAPK activation induces DIO3 levels in PTC cell lines}

To evaluate the role of MAPK activation in DIO3 regulation, experimental studies were performed in two distinct human PTC cell lines, $\mathrm{K} 1$ cells carrying the $B R A F^{V 600 E}$ mutation and TPC-1 cells harboring the RET/PTC1 rearrangement. We observed that, although DIO3 expression was readily detected in both cell lines (Fig. 1A), the levels of DIO3 mRNA and activity were significantly higher in $\mathrm{K} 1$ cells as compared to those observed in TPC- 1 cells $(0.32$ vs $0.11 \mathrm{AU}, P=0.007$; 14.9 vs $8.1 \mathrm{fmol} / \mathrm{mg}$.prot. $24 \mathrm{~h}, P=0.02$ respectively; Fig. $1 \mathrm{~A}$ and B).

Next, we evaluated the oncogenic effects of $B R A F^{V 600 E}$ mutation on $D I O 3$ reactivation. The incubation of K1 cells with the specific BRAF-mutated inhibitor, PLX 4032 $(3 \mu \mathrm{M})$, decreased ERK phosphorylation in $\sim 30 \%$ (Fig. $2 \mathrm{~A})$ as well as the DIO3 mRNA levels ( 2.2-fold, $P<0.001$; Fig. 2B). Similar results were obtained with higher PLX4032 doses, indicating that PLX4032-mediated decreases in ERK phosphorylation is not dose dependent (not shown). On the other hand, the incubation of K1 cells with increasing doses of MEK inhibitor (U0126, 10-20 $\mu \mathrm{M}$ ) for $24 \mathrm{~h}$ resulted in a dose-dependent reduction in ERK phosphorylation (Fig. 3A) and in DIO3 expression (10- to 12.5-fold, $P<0.001$; Fig. 3B). Likewise, the incubation of K1 cells with SB203580, a specific inhibitor of p38 protein, caused a dose-dependent reduction of phospho-p38 levels
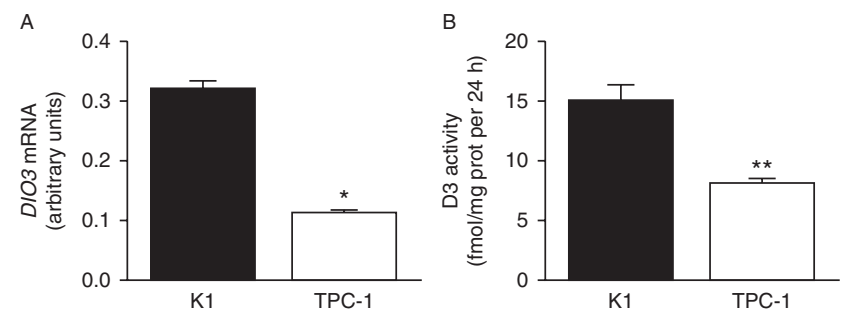

Figure 1

DIO3 mRNA levels (A) and activity (B) were readily detected in both PTC cell lines, $\mathrm{K} 1$ and TPC-1, and were significantly higher in $\mathrm{K} 1$ cells compared to TPC -1 cells. ${ }^{*} P<0.007 ; * * P=0.02$.

Published by Bioscientifica Ltd 
A

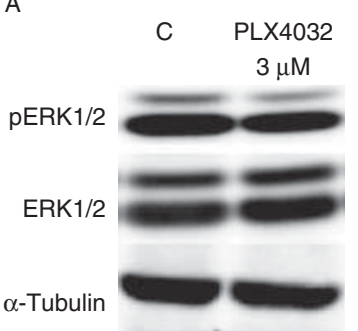

B

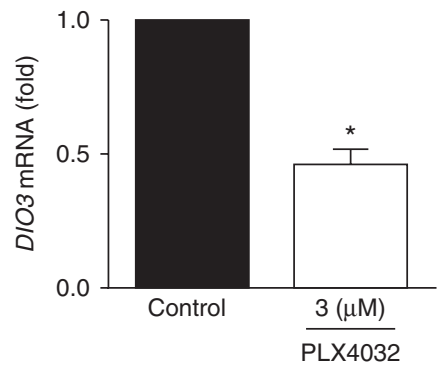

Figure 2

Incubation of $\mathrm{K} 1$ cells with the BRAF-mutated specific inhibitor, PLX4032 $(3 \mu \mathrm{M})$, for $24 \mathrm{~h}$ led to a reduction in the ERK phosphorylation $(\mathrm{A})$ and $D I O 3$ mRNA (B). ${ }^{*} P<0.001$

(Fig. 3C) as well as with decreases of DIO3 expression ( 2-fold, $P<0.001$; Fig. 3D).

Similar experiments were performed in TPC-1 cells. We observed a dose-dependent reduction in MEK and p38 phosphorylation in TPC-1 cells treated with specific inhibition of MEK (U0126) or p38 (SB203580) (Fig. 3E and $\mathrm{G}$ respectively). DIO3 expression was reduced in a dose-dependent fashion in the presence of both inhibitors (2.2- to 7-fold for U0126 and 2- to 3-fold for p38 respectively, $P<0.001$; Fig. $3 \mathrm{~F}$ and $\mathrm{H}$ ).

We also investigated the effect of MAPK genetic alterations on the DIO3 levels in 25 human PTC samples. Clinical and oncological features are detailed in Table 1.
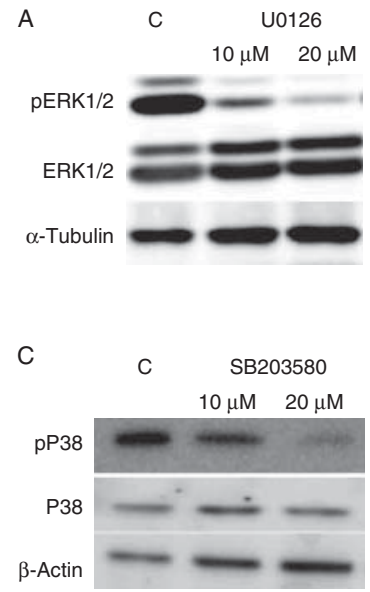
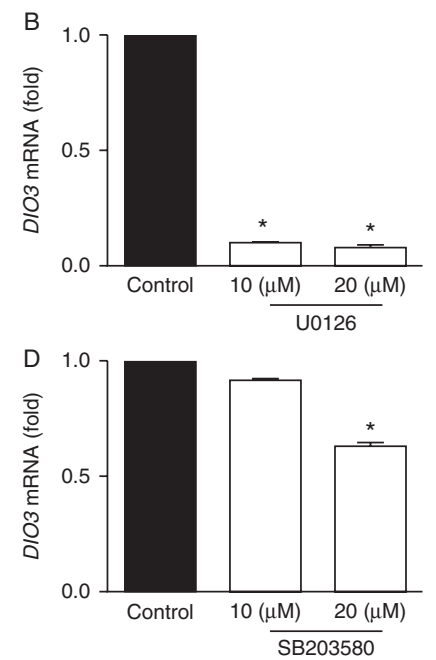

Mean age of patients was $37.04 \pm 14.7$ years, and $76 \%$ were women. The median tumor size was $2.5 \mathrm{~cm}(0.8-10.5) ; 13$ patients (52\%) had lymph node metastasis, while $6(24 \%)$ had distant metastasis at diagnosis. In total, 13 (52\%) out of the 25 were positive for the $B R A F^{V 600 E}$ mutation, $2(8 \%)$ carried RET/PTC1 rearrangement and 10 (40\%) were negative both genetic alterations. As previously shown (Romitti et al. 2012), DIO3 mRNA levels were significantly increased in PTC samples as compared with the levels observed in normal thyroid tissue $(P<0.001)$. Samples harboring $B R A F^{V 600 E}$ mutation displayed higher levels of DIO3 expression as compared with those observed in samples with RET/PTC1 rearrangement or negative for $\mathrm{BRAF}^{\mathrm{V} 600 \mathrm{E}}$ and RET/PTC1 alterations (7.97- vs 5.86- vs 5.85-fold respectively, $P<0.001$; Fig. 4). It is interesting, however, that the highest level of DIO3 expression was found in a sample negative for BRAF and RET/PTC1 (patient 18, Table 1).

To gain insights on D3 expression in PTC, we undertook immunohistochemical studies to evaluate D3 levels in PTC metastasis samples. Matched paraffinembedded thyroid tumor and metastatic lymph node tissues were obtained from two PTC patients $(n=18$ and $n=19$; Table 1 ). Remarkably, in both cases, the intensity of D3 staining was similar in tumor and metastatic tissue, indicating that D3 upregulation is a characteristic feature of this malignant neoplasia, occurring also in metastatic sites (Fig. 5A, B, C, D).
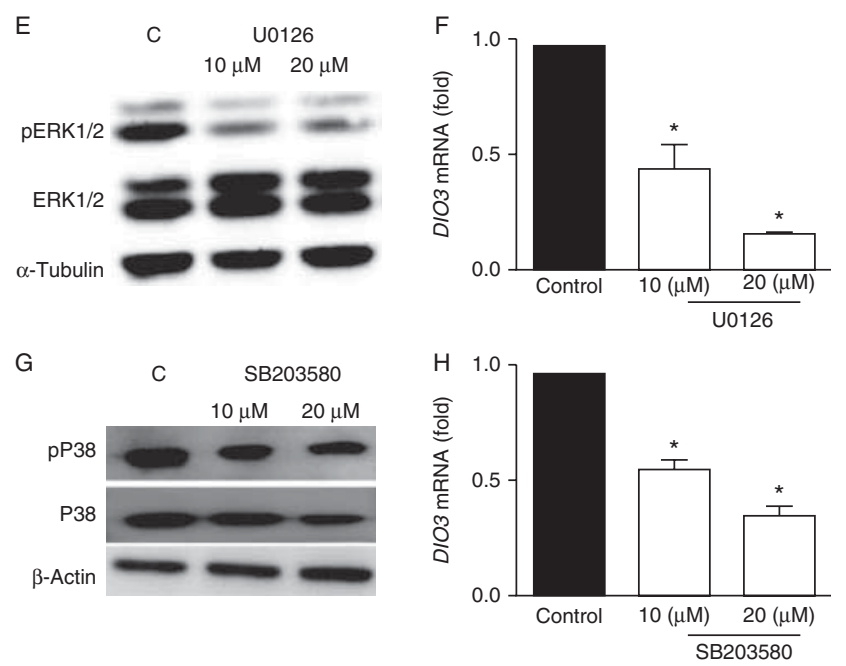

by SB203580 inhibitor in K1 cells inhibited p38 phosphorylation (C) while reduced the $D I O 3$ transcripts $(D)$. Similarly, the reduction of $p E R K(E)$ and pp38 (G) reduced the DIO3 levels in TPC-1 cells $\left({ }^{*} P<0.01\right)$.

phosphorylation of the ERK pathway (A) as well as caused a dosedependent reduction in the DIO3 levels (B). The inhibition of p38 protein 


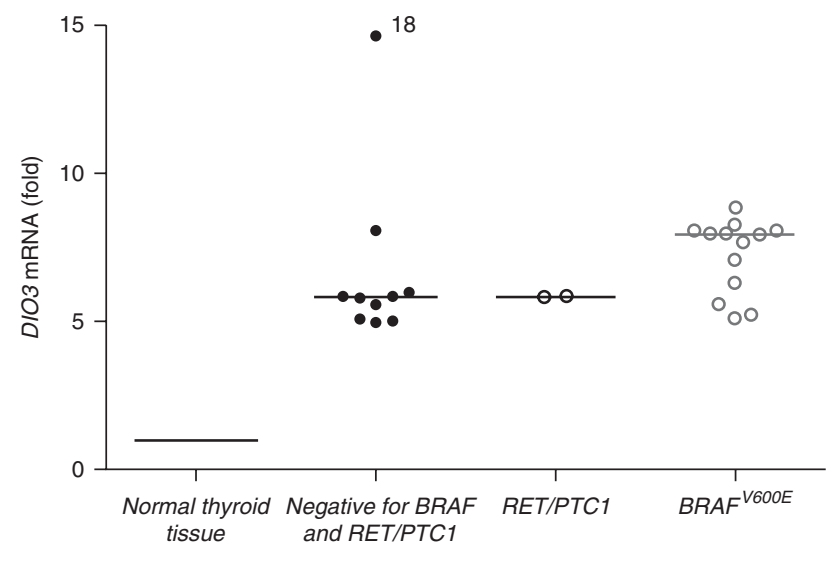

Figure 4

DIO3 mRNA was significantly increased in PTC samples as compared with thyroid normal tissue. Samples harboring BRAF ${ }^{V 600 E}$ mutation $(n=13)$ had higher levels of $D I O 3$ expression compared with samples presenting RET/PTC1 rearrangement $(n=2)$ or those negative for BRAF or RET/PTC1 mutations $(n=10)(P<0.001)$. The levels of DIO3 mRNA of PTC samples are expressed as the fold change relative to the reference levels of normal thyroid samples $(n=9)$, represented as 1 .

\section{Blockage of SHH pathway prevents DIO3 upregulation in PTC}

Next, we evaluated whether the SHH pathway and its downstream effector, GLI1, could be involved on DIO3 regulation in PTC. The $\mathrm{SHH}$ signaling was blocked using cyclopamine $(10 \mu \mathrm{M})$. We observed a reduction in the GLI1 protein (Fig. 6A and $\mathrm{C}$ for $\mathrm{K} 1$ and TPC cells respectively), followed by a marked decrease in the $\mathrm{DIO} 3$ levels in $\mathrm{K} 1$ ( $\sim 12$-fold, $P<0.001$; Fig. $6 \mathrm{~B})$ as well as in TPC1 cells ( $\sim 2.5$-fold, $P<0.001$; Fig. $6 \mathrm{D})$.

To identify whether MAPK and SHH cooperate in promoting DIO3 induction in PTC, we evaluated GLI1 protein expression under MEK and p38 proteins inhibition. We observed a reduction in GLI1 levels in K1 and TPC-1 cells after MAPK blockage with U0126 (Fig. 6E and $\mathrm{G}$ ) or SB203580 (Fig. 6F and H), indicating that these signaling pathways might cooperate on DIO3 regulation in PTC. Of note, however, the treatment of cells with cyclopamine has no effect on ERK or P38 phosphorylation (data not shown).

We then sought to explore the role of SHH signaling pathway on DIO3 reactivation. We have previously shown that MTC, a C-cell originated tumor, does not express D3 enzyme (Romitti et al. 2012). Low levels of DIO3 mRNA were detected in MTC-derived TT cells while a marked increase in DIO3 expression was observed in recombinant SHH-treated TT cells (2.5-fold, $P<0.001$; Fig. 6I). In contrast, recombinant $\mathrm{SHH}$ treatment significantly decreased DIO2 mRNA levels in TT cells (2.6-fold, $P<0.001$; Fig. 6J). It is intriguing, however, that recombinant $\mathrm{SHH}$ has no further effect on the already upregulated DIO3 expression in $\mathrm{K} 1$ and TPC-1 cells (data not shown).

\section{DIO3 silencing is associated with reduction in PTC cell proliferation}

To evaluate whether the DIO3 upregulation induces proliferation of neoplastic thyroid cells, we silenced the DIO3 gene in both PTC cell lines (K1 and TPC-1). The experiments were performed using a DIO3-specific siRNA (100 pmol) and GAPDH siRNA (40 pmol) as a positive control. K1 and TPC-1 cells were transfected with the siRNAs and maintained for $48 \mathrm{~h}$. The efficiency of siRNA transfection was established by the efficiency in silencing GAPDH gene (inhibition of 95\% in $\mathrm{K} 1$ and $~ 90 \%$ in TPC-1 cells, $P<0.001)$. DIO3 gene knockdown resulted in a $\sim 90 \%$ blockage of DIO3 transcripts in both cell lines $(P<0.001$; Fig. 7A and C). Interestingly, DIO3 inhibition was associated with significant reduction in the absolute cell number, as compared with control $(\sim 30 \%, P<0.01$; Fig. 7B and D) and decreased levels of cyclin D1 (Fig. 7E). Accordingly, further experiments showed that DIO3 silencing was associated with augmented proportion of cells in the G1 phase and a proportional reduction in the percentage of cells in S and G2 phases of cell cycle ( 30\%, P<0.005; Fig. 7F).

\section{Discussion}

In the present study, we have demonstrated that genetic alterations in the MAPK pathway effectors, such as $B R A F^{V 600 E}$ mutation and RET/PTC1 rearrangement, increase $\mathrm{DIO} 3$ levels. The $\mathrm{SHH}$ pathway is also involved in DIO3 upregulation once its signaling inhibition significantly reduces the DIO3 expression. Interestingly, siRNA-mediated DIO3 gene silencing decreases cyclin D1 levels while increasing the proportion of cells in the G1 phase of the cell cycle, reducing the proliferation of malignant thyroid cells.

A potential role of $\mathrm{D} 3$ in tumorigenesis has been postulated due to DIO3 upregulation in several benign and malignant tumors (Pallud et al. 1999, Huang et al. 2005, Dentice et al . 2007, 2012, Romitti et al. 2012). Studies performed in primary cultures of human fibroblasts showed that the DIO3 gene is induced by TGFB via SMAD and MAPK-dependent pathway (Huang et al. 2005). PTCs are known for carrying genetic alterations

Published by Bioscientifica Ltd. 

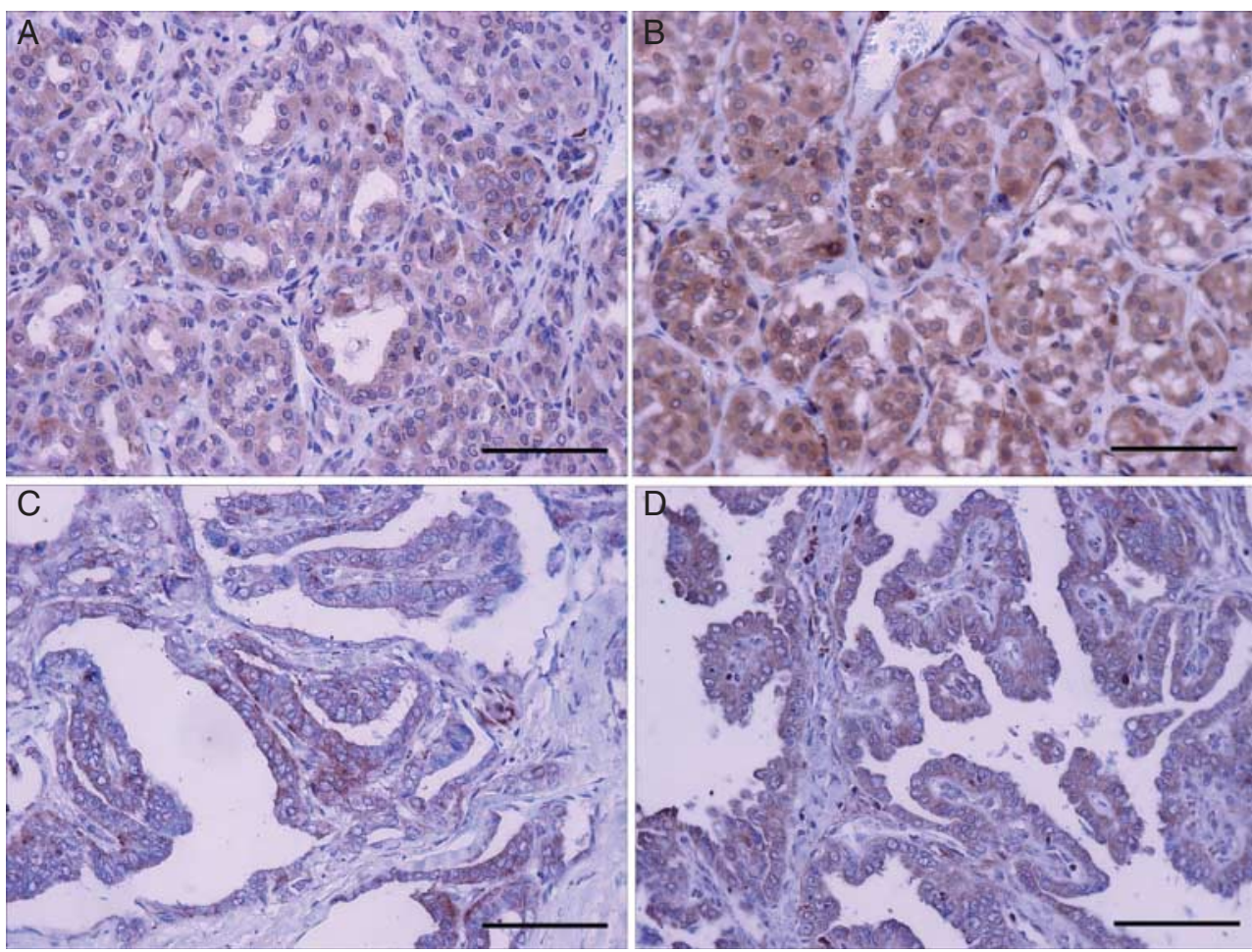

\section{Figure 5}

Representative micrographs of D3 brown-dark immunohistochemical staining samples of human PTC (A, B and C) and lymph node metastasis (B, C and D) tissues from two PTC patients $(n=18, \mathrm{~A}$ and $\mathrm{B}$, and $n=19$,

that lead to an aberrant and constitutive activation of MAPK pathway (Romitti et al. 2013). $\mathrm{BRAF}^{\mathrm{V} 600 \mathrm{E}}$ is an oncogenic protein with markedly elevated kinase activity that overactivates the MAPK pathway, especially ERK signaling transduction (Xing 2005, Chakravarty et al. 2011). Here, we show that $B R A F^{V 600 E}$ mutation is associated with the highest levels of DIO3 expression, as compared with RET/PTC1 (Fig. 1A and B), which seems to be mediated by the stronger ERK phosphorylation induced by this oncogene (Fig. 3A and B). On the other hand, we also observed that the p38 inhibition led to a more pronounced decrease in the DIO3 levels in TPC-1 than in K1 cells (Fig. 3G and $\mathrm{H} ; 3 \mathrm{E}$ and $\mathrm{F}$ respectively), thus suggesting that RET/PTC1 rearrangement induces the DIO3 levels mainly through this pathway. These observations are in agreement with previous studies which showed that RET/PTC1 rearrangement exerts its effects mainly by p38 phosphorylation (Hayashi et al. 2000, Mariggio et al. 2007). Consistently, we also observed a stronger induction of DIO3 expression in human PTC samples carrying the $B R A F^{V 600 E}$ mutation, as compared to those harboring the RET/PTC1 or none of these genetic alterations (Fig. 4). Interestingly,
( and D). Matched paraffin-embedded thyroid tumor and metastatic lymph node tissues showed similar intensity of D3 staining. Black bars represent $400 \times$ magnification.

similar D3 upregulation was observed in patient-matched tumor and lymph node metastasis, suggesting that the molecular mechanism responsible for D3 upregulation also occurs in the metastatic sites.

SHH signaling is critical for embryogenesis and other cellular processes such as proliferation and differentiation (Lum \& Beachy 2004). Disruption in SHH signaling results in various human diseases and seems to contribute to neoplastic processes. The $\mathrm{SHH}$ reactivation occurs in up to $25 \%$ of human tumors and has been associated with DIO3 induction (Dentice et al. 2007, Aw et al. 2014). Here, we show that the $\mathrm{SHH}$ signaling also modulates DIO3 expression in PTC cells. The use of the $\mathrm{SHH}$ pathway inhibitor, cyclopamine, promoted a marked decrease in DIO3 transcripts, indicating a direct effect of SHH/GLI1 signaling on gene regulation (Fig. 6A, B, C, D). Moreover, recombinant $\mathrm{SHH}$ treatment induced the DIO3 expression in TT cells (Fig. 6I). Interestingly, the blockage of the MAPK pathway, using MEK or p38 inhibitors, reduced the levels of GLI1, thus suggesting that the DIO3 expression in PTC might be regulated by cooperation between the MAPK and $\mathrm{SHH}$ pathways, as previously demonstrated in other

Published by Bioscientifica Ltd. 


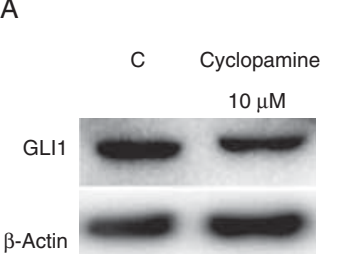

B

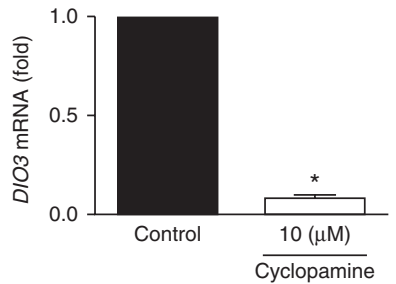

C

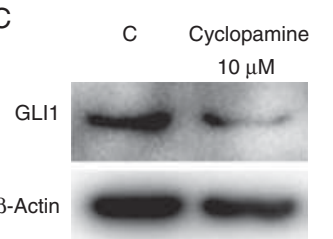

$\mathrm{E}$

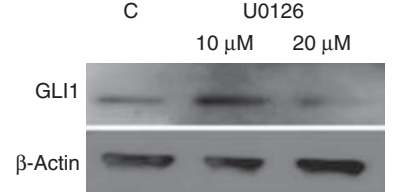

G

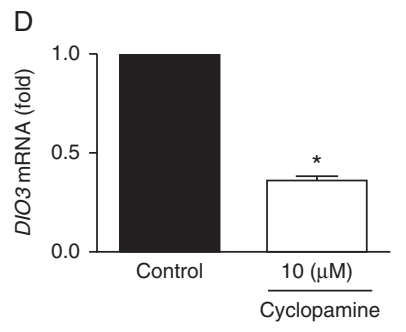

Figure 6

Incubation of K1 and TPC-1 cells with a chemical inhibitor of SHH pathway, cyclopamine $(10 \mu \mathrm{M})$, diminished GLI1 protein (A and $C)$ while decreased the $D I O 3$ levels in both cells ( $B$ and $D$ respectively; ${ }^{*} P<0.001$ ). Inhibition of MAPK proteins, MEK and $\mathrm{p} 38$, reduced the levels of GLI1 protein in K1 and

pathological conditions (Ji et al. 2007, Madhala-Levy et al. 2012). The oncogenic effects of the gene KRAS in pancreatic cancer cells are mediated by SHH/GLI1 activation, and the suppression of GLI activity led to selective attenuation in the oncogenic activity of mutant KRASexpressing cells (Ji et al. 2007). Of interest, two recent
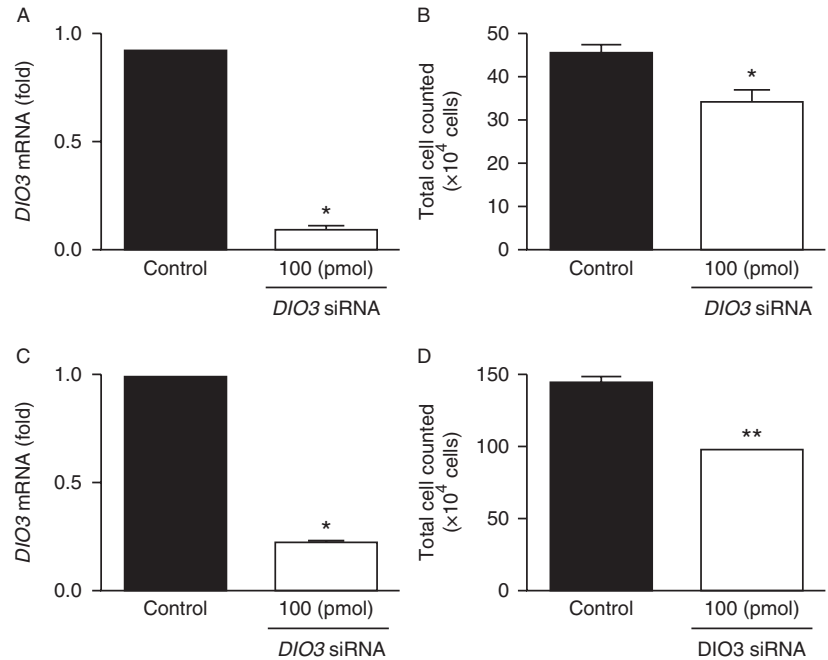

TPC- 1 cells $(E, F, G$ and $H$ ). Incubation with $1 \mu \mathrm{g} / \mathrm{ml}$ of recombinant $\mathrm{SHH}$ induced DIO3 mRNA (I) in TT cells while reduced the DIO2 levels (J; *P<0.001).

studies have evaluated the efficacy of the SHH inhibitor in patients with locally advanced or metastatic BCC (Sekulic et al. 2012, Tang et al. 2012). The treatment was associated with significant response rate in patients with metastatic tumors as well as in patients with locally advanced BCC (30 and 43\% respectively).
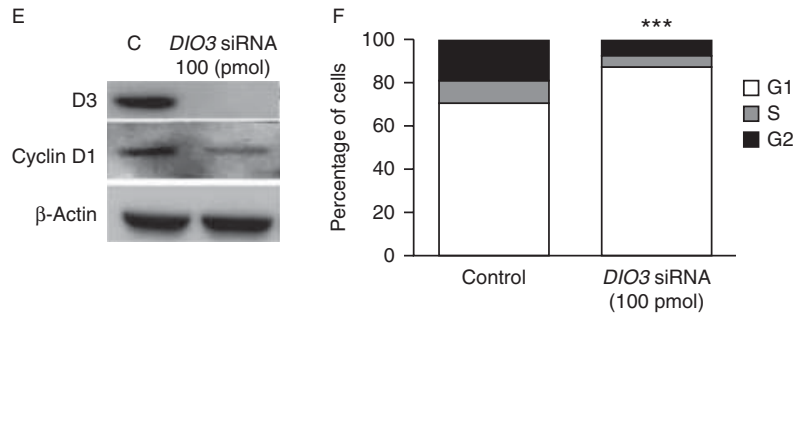

Figure 7

DIO3 knockdown resulted in $90 \%$ blockage of $D I O 3$ transcripts in $\mathrm{K} 1$ and TPC -1 cells (A and C respectively; ${ }^{*} P<0.001$ ). The reduction in DIO3 levels was also associated with a significant reduction in the absolute cell number

compared with controls ( $\mathrm{B}$ and $\mathrm{D} ; * * P<0.01$ ). The $\mathrm{DIO}$ silencing in $\mathrm{K} 1$ cells was associated with reduction in cyclin D1 protein $(E)$ while increased the proportion of cells in $\mathrm{G} 1$ phase of cell cycle $(\mathrm{F} ; * * * P<0.005)$. 
Previous studies have indicated that changes in the TH status might interfere with tumor pathogenesis. Clinical hypothyroidism seems to be a risk factor for several neoplasias such as liver cancer, thyroid malignancies, high-grade glioblastomas and human breast cancer (Reddi et al. 2007, Polyzos et al. 2008, Hassan et al. 2009, Angelousi et al. 2012). In contrast, increased TH levels have been associated with higher risk of esophageal, thyroid, breast and ovarian cancer development (Turkyilmaz et al. 2005, Rasool et al. 2014, Kunjumohamed et al. 2015). Changes in the intracellular TH concentration due to alterations in the deiodinases status seem to be critical for modulating cell proliferation and differentiation. Studies in clear cell renal cell carcinoma (ccRCC) have shown that the loss of DIO1 expression, mediated by miR-224 induction, resulted in diminishing intratumoral $\mathrm{T}_{3}$ concentration which contributes to the intracellular hypothyroidism observed in ccRCC (Boguslawska et al. 2011). Additionally, experimental studies in BCC and in colon tumor cells have shown that the increase in the DIO3 levels accompanied of DIO2 reduction would be associated with the induction of cell proliferation, by overexpression of cyclin D1. Accordingly, DIO3 knockdown caused a five-fold reduction in the growth of xenograft tumor, while the $\mathrm{T}_{3}$ addition promoted differentiation (Dentice et al. 2007, 2012). Nevertheless, the mechanisms underlying D3 and/or hypothyroidism induction of proliferation are still open to debate. Previous studies have shown that $T_{3}$ is involved in regulation of cyclin D1 expression (Nygård et al. 2003, Garcia-Silva \& Aranda 2004, Furumoto et al. 2005, Perri et al. 2014). In embryonic carcinoma cells, $\mathrm{T}_{3}$ treatment decreases the proliferation rate by arresting cells in the G1 and S phases while downregulates E2F1, both key regulators of proliferation. These $\mathrm{T}_{3}$-mediated effects depend on active TRs (Nygård et al. 2003). Accordingly, studies in mouse harboring a dominantly negative mutant $\mathrm{TH}$ receptor (TR $\beta P V / P V)$ suggest that the absence of TR $\beta$, and consequent lacking $\mathrm{T}_{3}$ signaling, induces cyclin D1 expression, leading to the activation of the CDK/retinoblastoma (RB)/E2F pathway that mediates, at least in part, the aberrant proliferation of thyroid cells (Furumoto et al. 2005). In this study, we show that the siRNA-mediated DIO3 gene attenuation decreases the number and cyclin D1 levels (Fig. 7A, B, C, D, E), followed by a partial G1 phase cell cycle arrest (Fig. 7F). These results further support a pivotal role of $\mathrm{DIO} 3$ overexpression in neoplastic cell proliferation.

In conclusion, we have demonstrated that DIO3 expression is modulated by MAPK genetic alterations in
PTC. SHH pathway activation might also be involved in DIO3 upregulation by a signaling cooperation with MAPK pathway. Finally, the reduction on cell proliferation rate in D3-depleted PTC cells supports the hypothesis that the decrease in intracellular TH levels might be associated with tumor growth and aggressiveness.

\section{Supplementary data}

This is linked to the online version of the paper at http://dx.doi.org/10.1530/ ERC-15-0162.

\section{Declaration of interest}

The authors declare that there is no conflict of interest that could be perceived as prejudicing the impartiality of the research reported.

\section{Funding}

This work was supported by Coordenação de Aperfeiçoamento de Pessoal de Nível Superior (CAPES), Conselho Nacional de Desenvolvimento Científico e Tecnológico (CNPq), Fundação de Apoio a Pesquisa do Rio Grande do Sul (FAPERGS) and Fundo de Incentivo a Pesquisa do Hospital de Clínicas de Porto Alegre (FIPE), Brazil.

\section{References}

Angelousi AG, Anagnostou VK, Stamatakos MK, Georgiopoulos GA \& Kontzoglou KC 2012 Mechanisms in endocrinology: primary HT and risk for breast cancer: a systematic review and meta-analysis. European Journal of Endocrinology 166 373-381. (doi:10.1530/EJE-11-0838)

Aw DK, Sinha RA, Tan HC, Loh LM, Salvatore D \& Yen PM 2014 Studies of molecular mechanisms associated with increased deiodinase 3 expression in a case of consumptive hypothyroidism. Journal of Clinical Endocrinology and Metabolism 99 3965-3971. (doi:10.1210/jc. 2013-3408)

Boguslawska J, Wojcicka A, Piekielko-Witkowska A, Master A \& Nauman A $2011 \mathrm{MiR}-224$ targets the $3^{\prime}$ UTR of type $15^{\prime}$-iodothyronine deiodinase possibly contributing to tissue hypothyroidism in renal cancer. PLoS ONE 6 e24541. (doi:10.1371/journal.pone.0024541)

Carlomagno F, Salvatore D, Santoro M, de Franciscis V, Quadro L, Panariello L, Colantuoni V \& Fusco A 1995 Point mutation of the RET proto-oncogene in the TT human medullary thyroid carcinoma cell line. Biochemical and Biophysical Research Communications $\mathbf{2 0 7}$ 1022-1028. (doi:10.1006/bbrc.1995.1287)

Chakravarty D, Santos E, Ryder M, Knauf JA, Liao XH, West BL, Bollag G, Kolesnick R, Thin TH, Rosen N et al. 2011 Small-molecule MAPK inhibitors restore radioiodine incorporation in mouse thyroid cancers with conditional BRAF activation. Journal of Clinical Investigations 121 4700-4711. (doi:10.1172/JCI46382)

Dentice M \& Salvatore D 2011 Deiodinases: the balance of thyroid hormone: local impact of thyroid hormone inactivation. Journal of Endocrinology 209 273-282. (doi:10.1530/JOE-11-0002)

Dentice M, Luongo C, Huang S, Ambrosio R, Elefante A, Mirebeau-Prunier D, Zavacki AM, Fenzi G, Grachtchouk M, Hutchin M et al. 2007 Sonic hedgehog-induced type 3 deiodinase blocks thyroid hormone action enhancing proliferation of normal and malignant keratinocytes. PNAS 104 14466-14471. (doi:10.1073/pnas.0706754104) 
Dentice M, Luongo C, Ambrosio R, Sibilio A, Casillo A, Iaccarino A Troncone G, Fenzi G, Larsen PR \& Salvatore D 2012 Beta-Catenin regulates deiodinase levels and thyroid hormone signaling in colon cancer cells. Gastroenterology 143 1037-1047. (doi:10.1053/j.gastro. 2012.06.042)

Fagin JA \& Mitsiades N 2008 Molecular pathology of thyroid cancer: diagnostic and clinical implications. Best Practice \& Research. Clinical Endocrinology \& Metabolism 22 955-969. (doi:10.1016/j.beem. 2008.09.017)

Furumoto H, Ying H, Chandramouli GV, Zhao L, Walker RL, Meltzer PS, Willingham MC \& Cheng SY 2005 An unliganded thyroid hormone beta receptor activates the cyclin D1/cyclin-dependent kinase/retinoblastoma/E2F pathway and induces pituitary tumorigenesis. Molecular Cell Biology 25 124-135. (doi:10.1128/MCB.25.1.124-135.2005)

Fuziwara CS \& Kimura ET 2014 High iodine blocks a Notch/miR-19 loop activated by the BRAF(V600E) oncoprotein and restores the response to TGFbeta in thyroid follicular cells. Thyroid 24 453-462. (doi:10.1089/ thy.2013.0398)

Garcia-Silva S \& Aranda A 2004 The thyroid hormone receptor is a suppressor of ras-mediated transcription, proliferation, and transformation. Molecular and Cellular Biology 24 7514-7123. (doi:10.1128/MCB.24.17.7514-7523.2004)

Geraldo MV, Yamashita AS \& Kimura ET 2012 MicroRNA miR-146b-5p regulates signal transduction of TGF-b by repressing SMAD4 in thyroid cancer. Oncogene 31 1910-1922. (doi:10.1038/onc.2011.381)

Hassan MM, Kaseb A, Li D, Patt YZ, Vauthey JN, Thomas MB, Curley SA, Spitz MR, Sherman SI, Abdalla EK et al. 2009 Association between hypothyroidism and hepatocellular carcinoma: a case-control study in the United States. Hepatology 49 1563-1570. (doi:10.1002/hep.22793)

Hayashi H, Ichihara M, Iwashita T, Murakami H, Shimono Y, Kawai K, Kurokawa K, Murakumo Y, Imai T, Funahashi H et al. 2000 Characterization of intracellular signals via tyrosine 1062 in RET activated by glial cell line-derived neurotrophic factor. Oncogene 19 4469-4475. (doi:10.1038/sj.onc.1203799)

Hedinger C, Williams ED \& Sobin LH 1989 The WHO histological classification of thyroid tumors: a commentary on the second edition. Cancer 63 908-911. (doi:10.1002/1097-0142(19890301)63:5< 908::AID-CNCR2820630520>3.0.CO;2-I)

Huang Y, Prasad M, Lemon WJ, Hampel H, Wright FA, Kornacker K, LiVolsi V, Frankel W, Kloos RT, Eng C et al. 2001 Gene expression in papillary thyroid carcinoma reveals highly consistent profiles. PNAS 98 15044-15049. (doi:10.1073/pnas.251547398)

Huang HC, Liu SY, Liang Y, Liu Y, Li JZ \& Wang HY 2005 Transforming growth factor-beta1 stimulates matrix metalloproteinase-9 production through ERK activation pathway and upregulation of Ets-1 protein. Zhonghua Bing Li Xue Za Zhi 85 328-331.

Ji Z, Mei FC, Xie J \& Cheng X 2007 Oncogenic KRAS activates hedgehog signaling pathway in pancreatic cancer cells. J Biol Chem $\mathbf{2 8 2}$ 14048-14055. (doi:10.1074/jbc.M611089200)

Kim WG \& Cheng SY 2013 Thyroid hormone receptors and cancer. Biochimica Biophysica Acta 1830 3928-3936. (doi:10.1016/j.bbagen. 2012.04.002)

Kimura ET, Nikiforova MN, Zhu Z, Knauf JA, Nikiforov YE \& Fagin JA 2003 High prevalence of BRAF mutations in thyroid cancer: genetic evidence for constitutive activation of the RET/PTC-RAS-BRAF signaling pathway in papillary thyroid carcinoma. Cancer Research 63 1454-1457. (doi:10.1002/pmic.201300476)

Kunjumohamed FP, Al-Busaidi NB, Al-Musalhi HN, Al-Shereiqi SZ \& Al-Salmi IS 2015 The prevalence of thyroid cancer in patients with hyperthyroidism. Saudi Medical Journal 36 874-877. (doi:10.15537/smj. 2015.7.11463)

Lum L \& Beachy PA 2004 The Hedgehog response network: sensors, switches, and routers. Science 304 1755-1759. (doi:10.1126/science. 1098020)

Madhala-Levy D, Williams VC, Hughes SM, Reshef R \& Halevy O 2012 Cooperation between Shh and IGF-I in promoting myogenic proliferation and differentiation via the MAPK/ERK and PI3K/Akt pathways requires Smo activity. Journal of Cell Physiology 227 1455-1464. (doi:10.1002/jcp.22861)

Maia AL, Goemann IM, Meyer EL \& Wajner SM 2011 Deiodinases: the balance of thyroid hormone: type 1 iodothyronine deiodinase in human physiology and disease. Journal of Endocrinology 209 283-297. (doi:10.1530/JOE-10-0481)

Mariggio S, Filippi BM, Iurisci C, Dragani LK, De Falco V, Santoro M \& Corda D 2007 Cytosolic phospholipase A2 alpha regulates cell growth in RET/PTC-transformed thyroid cells. Cancer Research 67 11769-11778. (doi:10.1158/0008-5472.CAN-07-1997)

Meyer EL, Wagner MS \& Maia AL 2007 Iodothyronine deiodinases expression in thyroid neoplasias. Arquivos Brasileiros de Endocrinologia \& Metabologia 51 690-700. (doi:10.1590/S0004-27302007000500006)

Murakami M, Araki O, Hosoi Y, Kamiya Y, Morimura T, Ogiwara T, Mizuma H \& Mori M 2001 Expression and regulation of type II iodothyronine deiodinase in human thyroid gland. Endocrinology 142 2961-2967. (doi:10.1210/endo.142.7.8280)

Nygård M, Wahlström GM, Gustafsson MV, Tokumoto YM \& Bondesson M 2003 Hormone-dependent repression of the E2F-1 gene by thyroid hormone receptors. Molecular Endocrinology 17 79-92. (doi:10.1210/me. 2002-0107)

Pallud S, Ramauge M, Gavaret JM, Lennon AM, Munsch N, St Germain DL, Pierre M \& Courtin F 1999 Regulation of type 3 iodothyronine deiodinase expression in cultured rat astrocytes: role of the Erk cascade. Endocrinology 140 2917-2923. (doi:10.1210/endo.140.6.6834)

Pellegriti G, Frasca F, Regalbuto C, Squatrito S \& Vigneri R 2013 Worldwide increasing incidence of thyroid cancer: update on epidemiology and risk factors. Journal of Cancer Epidemiology 2013 965212. (doi:10.1155/ 2013/965212)

Perri A, Catalano S, Bonofiglio D, Vizza D, Rovito D, Qi H, Aquila S, Panza S, Rizza P, Ando LM et al. 2014 T3 enhances thyroid cancer cell proliferation through TRbeta1/Oct-1-mediated cyclin D1 activation. Molecular and Cellular Endocrinology 382 205-217. (doi:10.1016/j.mce. 2013.10.001)

Pinto M, Soares P \& Ribatti D 2011 Thyroid hormone as a regulator of tumor induced angiogenesis. Cancer Letters 301 119-126. (doi:10.1016/j.canlet.2010.11.011)

Polyzos SA, Kita M, Efstathiadou Z, Poulakos P, Slavakis A, Sofianou D, Flaris N, Leontsini M, Kourtis A \& Avramidis A 2008 Serum thyrotropin concentration as a biochemical predictor of thyroid malignancy in patients presenting with thyroid nodules. Journal of Cancer Research and Clinical Oncology 134 953-960. (doi:10.1007/s00432-008-0373-7)

Porlan E, Vega S, Iglesias T \& Rodríguez-Peña A 2004 Unliganded thyroid hormone receptor beta 1 inhibits proliferation of murine fibroblasts by delaying the onset of the G1 cell-cycle signals. Oncogene 23 8756-8765. (doi:10.1038/sj.onc.1208126)

Rasool M, Naseer MI, Zaigham K, Malik A, Riaz N, Alam R, Manan A, Sheikh IA \& Asif M 2014 Comparative Study of Alterations in Tri-iodothyronine (T3) and Thyroxine (T4) Hormone Levels in Breast and Ovarian Cancer. Pakistan Journal of Medical Sciences 30 1356-1360. (doi:10.12669/pjms.306.5294)

Reddi HV, McIver B, Grebe SK \& Eberhardt NL 2007 The paired box-8/ peroxisome proliferator-activated receptor-gamma oncogene in thyroid tumorigenesis. Endocrinology 148 932-935. (doi:10.1210/ en.2006-0926)

Romitti M, Wajner SM, Zennig N, Goemann IM, Bueno AL, Meyer EL \& Maia AL 2012 Increased type 3 deiodinase expression in papillary thyroid carcinoma. Thyroid 22 897-904. (doi:10.1089/thy.2012.0031)

Romitti M, Ceolin L, Siqueira DR, Ferreira CV, Wajner SM \& Maia AL 2013 Signaling pathways in follicular cell-derived thyroid carcinomas (review). International Journal of Oncology 42 19-28. (doi:10.3892/ijo. 2012.1681)

Saiselet M, Floor S, Tarabichi M, Dom G, Hebrant A, van Staveren WC \& Maenhaut C 2012 Thyroid cancer cell lines: an overview. Frontiers in Endocrinology 3 133. (doi:10.3389/fendo.2012.00133)

Published by Bioscientifica Ltd. 
Sapio MR, Posca D, Raggioli A, Guerra A, Marotta V, Deandrea M, Motta M, Limone PP, Troncone G, Caleo A et al. 2007 Detection of RET/PTC, TRK and BRAF mutations in preoperative diagnosis of thyroid nodules with indeterminate cytological findings. Clinical Endocrinology 66 678-683. (doi:10.1111/j.1365-2265.2007.02800.x)

Schweppe RE, Klopper JP, Korch C, Pugazhenthi U, Benezra M, Knauf JA, Fagin JA, Marlow LA, Copland JA, Smallridge RC et al. 2008

Deoxyribonucleic acid profiling analysis of 40 human thyroid cancer cell lines Reveals Cross-Contamination Resulting in Cell Line Redundancy and Misidentification. Journal of Clinical Endocrinology and Metabolism 93 4331-4341. (doi:10.1210/jc.2008-1102)

Sekulic A, Migden MR, Oro AE, Dirix L, Lewis KD, Hainsworth JD, Solomon JA, Yoo S, Arron ST, Friedlander PA et al. 2012 Efficacy and safety of vismodegib in advanced basal-cell carcinoma. New England Journal of Medicine 366 2171-2179. (doi:10.1056/NEJMoa1113713)

de Souza Meyer EL, Dora JM, Wagner MS \& Maia AL 2005 Decreased type 1 iodothyronine deiodinase expression might be an early and discrete event in thyroid cell dedifferentation towards papillary carcinoma. Clinical Endocrinology 62 672-678. (doi:10.1111/j.1365-2265.2005. 02277.x)

Tang JY, Mackay-Wiggan JM, Aszterbaum M, Yauch RL, Lindgren J, Chang K, Coppola C, Chanana AM, Marji J, Bickers DR et al. 2012 Inhibiting the hedgehog pathway in patients with the basal-cell nevus syndrome. New England Journal of Medicine 3662180-2188. (doi:10.1056/NEJMoa1113538)

Turkyilmaz A, Eroglu A, Aydin Y, Yilmaz O \& Karaoglanoglu N 2005 A new risk factor in oesophageal cancer aetiology: hyperthyroidism. Acta Chirurgica Belgica 10 533-536.

Wajner SM, Goemann IM, Bueno AL, Larsen PR \& Maia AL 2011 IL-6 promotes nonthyroidal illness syndrome by blocking thyroxine activation while promoting thyroid hormone inactivation in human cells. Journal of Clinical Investigations 121 1834-1845. (doi:10.1172/JCI44678)

Xing M 2005 BRAF mutation in thyroid cancer. Endocrine Related Cancer 12 245-262. (doi:10.1677/erc.1.0978)

Received in final form 14 November 2015

Accepted 8 December 2015
(C) 2016 Society for Endocrinology Printed in Great Britain
Published by Bioscientifica Ltd. 